\title{
A ENFERMEIRA OBSTÉTRICA E A PREVENÇÃO NO RISCO OCUPACIONAL DE CONTAMINAÇÃO PELO VÍRUS HIV EM CENTRO OBSTÉTRICO
}

\author{
Neide de Souza Praça* \\ João L uiz Grandi**
}

\begin{abstract}
RESUMO - Mostra a preocupação das instituições de saúde frente ao risco ocupacional de contaminação pelo HIV em Centro Obstétrico. Analisa o papel da enfermeira obstétrica e sugere procedimentos para a diminuição do risco de contaminação pessoal no atendimento à parturiente e ao recém-nascido.
\end{abstract}

\begin{abstract}
It shows the preoccupation of the health institutions face to the occupational risk of contamination by HIV Obstetric Center. Analyses the role of the obstetric nurse and sugests procedures to decrease the risk of personal contamination in the assistance to the parturient woman and the new-born.
\end{abstract}

\section{INTRODUÇÃO}

Primeiramente descrita ao final da década de 70, a Síndrome da Imunodeficiência Adquirida (AIDS), provavelmente se disseminou a partir do Zaire, na África, e atualmente se constitui em importante problema de saúde pública em todo o mundo.

LISKIN \& BLACKBURN (1987) citam que a US-CDC (US - Center for Disease Control) define a AIDS como uma síndrome que se caracteriza por infecções oportunistas que envolvem risco de vida e/ou formas de câncer que ocorrem em pessoas com problemas imunológicos, inexplicáveis por outras circunstâncias.

Segundo FRIEDL AND \& KLEIN (1987), o vírus causador desta síndrome foi isolado em 1983 e recebe atualmente o nome de HIV (vírus da imunodeficiência humana). Conforme LISKIN \& BL ACK BURN (1987), este retrovírus infecta os linfócitos T auxiliares ( $\mathrm{T}$ helper) ou $\mathrm{T}_{4}$, bem como as células $\mathrm{B}$, macrófagos e as células nervosas, como conseqüência, há prejuízo na produção de anticorpos no indivíduo infectado e na maturação de vários tipos de células do seu sistema imunitário, surgindo a deficiência imunológica.

De acordo com os mesmos autores, a maioria das pessoas infectadas não apresenta sintomatologia e não sabe que é portadora do vírus, embora todos os infectados transmitam o HIV. O vírus pode permanecer inativo na célula do hospedeiro por muitos anos e por estímulo de uma resposta imunológica pode ser ativado a produzir novos vírus.

O HIV tem sido isolado de vários fluídos corporais, tais com lágrima, saliva, colostro, urina e secreções vaginais; no entanto, conforme LISKIN \& BLACKBURN (1987), suas maiores concentrações são encontradas no sangue, esperma, líquido cérebroespinal e leite materno e são estas as vias de transmissão comprovadas até o momento.

O HIV pode portanto, ser transmitido pelas vias sexual, sanguínea e perinatal, sendo considerados como grupos de risco: os homossexuais, os bissexuais masculinos, os hemofílicos, os receptores de transfusões sanguíneas, os usuários de drogas injetáveis, os parceiros sexuais de indivíduos pertencentes a grupos de risco e os bebês nascidos de mães soropositivas para o HIV.

STONE \& COWAN (1987) acrescentam à relação, as mulheres que possam ter recebido sêmem infectado por inseminação artificial e aquelas que tenham recentemente tido atividade sexual na África Central.

A cura da AIDS ou seu tratamento eficaz ainda não foram obtidos e, conforme LISKIN \& BL ACKBURN (1987), esta dificuldade se deve ao fato da facilidade do HIV em mudar rapidamente a estrutura genética de suas proteínas externas e assim escapar de ser reconhecido pelo sistema imunológico do indivíduo.

Ao analisar as vias de transmissão do HIV, LISKIN \& BLACKBURN (1987) acreditam que nas relações sexuais onde estejam envolvidos múltiplos parceiros, há aumento de probabilidade de contato com alguém infectado e, portanto, é maior o risco de contaminação nestes casos. No entanto, têm dúvidas quanto ao risco de infecção associado a um único ato sexual com alguém infectado.

As recomendações para evitar a transmissão do HIV pela via sexual se voltam ao uso de preservativos, à redução do número de parceiros sexuais e à evitar manter relações com pessoas dos grupos de risco ou suspeitos de estarem infectados.

Indivíduos contaminados através de transf usão de sangue e produtos sanguíneos representam uma pequena, porém importante proporção do número total de casos FRIEDL AND \& KLEIN (1987). A quantidade de vírus inoculada, bem como a dose infectante, tornam-se de difícil determinação pela dificuldade em quantificar o vírus "in vivo" e portanto, a dose mínima

* Enfermieira, Auxiliar de Ensino do Departamento de Enfermgem Materno-Infantil e Psiquiátrica da Escola de Enfermagem da Universidade de São Paulo. Mestranda em Enfermagem Obstétrica e Neonatal da Escola de Enfermagem da Universidade de São Paulo.

** Enfermeiro da Divisão de Educação e Treinamento do Centro de Referência para AIDS da Secretaria de Estado da Saúde de São Paulo. 
capaz de estabelecer a infecção no homem é desconhecida.

No Brasil, 32,5\% dos casos de AIDS em adoles centes e adultos do sexo feminino ocorridos no período de 1982 a dezembro de 1987, foram causados por transfusão de sangue e de componentes sanguíneos (MINISTÉRIO DA SAÚDE, 1987-a).

Para FRIEDL AND \& KLEIN (1987), uma pequena e única inoculação do HIV transferida por via parenteral associa-se a um muito baixo risco. Inoculação acidental por picada de agulha entre trabalhadores da área da saúde, têm sido objeto de estudos e mesmo se desconhecendo a quantidade inoculada, estima-se que esta se ja extremamente pequena $(1,4 \mu \mathrm{l})$.

São freqüentes estudos envolvendo grandes números de trabalhadores da área de saúde que receberam inoculação parenteral acidental ou em membros mucosas com sangue contaminado pelo vírus. Os resultados obtidos relacionam os poucos casos positivos a fatores pessoais de risco alheios às tarefas ocupacionais. Por outro lado, o acompanhamento prolongado dos envolvidos em tais estudos, mostra que os mesmos permanecem soronegativos para o HIV.

LEADS (1984) cita estudo do CDC ef etuado em 1983, pesquisando 51 funcionários da saúde com exposições parenterais ou a membranas mucosas por fluídos corpóreos potencialmente infectados de pacientes com AIDS ou suspeitos, no período de abril de 1981 a novembro de 1983 onde $53 \%$ das exposições ocorreram nas enfermarias, $24 \%$ em UTI, $14 \%$ em laboratório e $10 \%$ em sala de operação e necrotério. As formas de infecção envolvidas foram: ferimentos por picadas de agulhas (65\%), ferimentos com instrumentos cortantes (16\%), exposições de mucosas (14\%) e contaminação de lesões abertas de pele com fluídos corpóreos potencialmente infectados (6\%).

$\mathrm{Na}$ literatura há somente dois registros de profissionais de saúde que se tornaram soropositivos após acidente parenteral com agulha contaminada com sangue de paciente com AIDS. Trata-se de um enfermeiro na Inglaterra e um profissional de saúde na África.

FUCK S et alii (1987) explicam a baixa freqüência de soroconversão em trabalhadores da saúde após ferimento por picada de agulha, a partir da conclusão obtida por um estudo cujo resultado sugere que o estado de ativação dos linfócitos $\mathrm{T}$ e macrófagos do indivíduo que recebe a inoculação é de extrema importância na determinante da inf ecção e associa-se à quantidade de vírus a que o indivíduo está sendo exposto.

Indivíduos que já têm linfócitos $\mathrm{T}$ e macrófagos ativados, imediatamente replicam o vírus ao se tornarem infectados. Isto contribui para reforçar o fato da baixa produtividade do HIV nos trabalhadores que sof reram acidentes ocupacionais.

O MINISTÉRIO DA SAÚDE (1987b) cita que a transmissão do HIV por via perinatal ocorre em menor magnitude do que por via sexual e sanguínea.

Para FRIEDL AND \& KLEIN (1987), o HIV pode ser transmitido de mulheres infectadas para o seu concepto por três possíveis vias:

- no útero através da circulação materna;

- durante o trabalho de parto e parto por inoculação ou ingestão de sangue e outros fluídos infectados; e

- para o lactente, pelo leite materno infectado.
Um mesmo bebê pode se infectar por uma ou todas as vias, embora não se conheça a eficiência relativa e nem a freqüência de cada via.

De acordo com o MINISTÉRIO DA SAÚDE (1987b), as taxas reais de transmissão do HIV da mãe para o bebê não são conhecidas, embora PYUN et alii (1987) estimem em 65 a $95 \%$ os bebês contaminados nascidos de mães infectadas; STONE \& COWAN (1987) consideram a taxa de 50 a $60 \%$, enquanto que LISKIN \& BLACKBURN (1987) estimam em 20 a $50 \%$. Estes autores citam que se desconhecem os fatores que aumentam o risco de transmissão do vírus da mulher infectada para o filho; desconhecendo-se também a probabilidade de que uma mulher contaminada tansmita o vírus ao filho.

PYUN et alii (1987) referem que mulheres in fectadas pelo HIV produzem IgG e quando grávidas, estas imunoglobulinas são transferidas ao feto via transplacentária. Como conseqüência, o sangue do cordão, quando submetido aos testes ELISA e Western Blot, resulta positivo para o anticorpo, Este fato dificulta demonstrar a infecção no neonato que pela própria debilidade fisiológica e imunitária apresenta uma resposta menos vigorosa ao anticorpo e mais limitada à infecção pelo HIV.

STONE \& COWAN (1987) citam que a gestação é reconhecida como tendo ef eitos adversos na saúde de mulheres assintomaticamente positivas para o HIV. Elas têm maior probabilidade de desenvolver o mais alto grau de AIDS se comparadas à população não grávida è esta proporção é de $65 \%$ para 30 ou $50 \%$ destas.

No Brasil, dos casos de AIDS confirmados em menores de 15 anos, no período de 1982 a dezembro de 1987, 20\% ocorreram por transmissão perinatal (MINISTÉRIO DA SAÚDE, 1987c )

GRIMES (1987), citando as recomendações do CDC para a AIDS, refere que este aconselha as mulheres infectadas pelo HIV a não conceberem, como forma de diminuição da transmissão perinatal.

Pela relevância pertinente aos riscos a que a população atuante nas unidades hospitalares está sujeita em relação ao contato com sangue e fluídos corpóreos dos pacientes nelas tratados; pelo desconhecimento da positividade ou não do HIV nesta população; o CDC recomenda que o sangue e outros fluídos corpóreos "de todos os pacientes" sejam tratados como poten cialmente infectados.

A SECRETARIA DE ESTADO DA SAÚDE (1988) do Estado de São Paulo, considera como potencialmente infectado todo paciente em atendimento ambulatorial, odontológico e hospitalar nos serviços de emergência e na anatomia patológica e necrotério.

De acordo com o CDC, citado por LEADS (1984), acima da terça parte das exposições acidentais ocupacionais nos estudos efetuados nos EUA, poderiam ter sido evitadas se fossem seguidas as recomendações de precauções.

Segundo STONE \& COWAN (1987), é difícil a identificação de mulheres incluídas nos vários grupos de risco, portanto, concluem que o caminho mais efetivo para controlar a inf ecção é a prevenção, para onde devem convergir todos os recursos.

Vários autores citam que pode existir um maior risco de transmissão do HIV por exposição parenteral nos países do Terceiro Mundo. Tal fato se deve à falta 
de treinamento de pessoal que administra medicamentos, à precariedade do equipamento disponível e às práticas inadequadas de esterilização.

Os órgãos de saúde pesquisados pela bibliografia (MINISTÉRIO DA SAUDE, 1986a; 1986b .1987c) recomendam que as medidas de precaução por eles elaboradas devem ser aplicadas no atendimento hospitalar a níveis ambulatorial e de emergência.

L IMA (1986) preconiza que a prevenção junto ao pessoal da área de saúde, deve ser realizado através de normas de precauções no manuseio de sangue, fluídos, secreções e excreções. Refere também que o funcionário da saúde deve estar ciente de que não há nenhuma evidência de contágio através de contatos sociais, bem como pelo ar, alimentos e objetos.

A SECRETARIA DE ESTADO DA SAÚDE (1988) do Estado de São Paulo destaca a importância da educação continuada no atendimento aos pacientes em geral, como meio de prevenção da AIDS para os profissionais da saúde.

$\mathrm{O}$ atendimento obstétrico caracteriza-se por seu caráter emergencial. Exige, portanto, a adoção de medidas preventivas para o vírus HIV por parte da equipe que atende à parturiente, puérpera e recém-nascido.

Embora o risco de positividade dos testes de detecção de anticorpo anti-HIV seja baixo para os contactuantes ocupacionais para com o vírus, este fato não invalida a importância da prevenção.

Considerando o aumento do percentual de mulheres contaminadas pelo HIV e seu fator de reprodução, foi desenvolvido o presente estudo que teve por objetivos:

- verificar a utilização, pelo pessoal de enfermagem que atende à parturiente, dos recursos fornecidos pela instituição de saúde na prevenção da contaminação pelo HIV.

\section{METODOLOGIA}

O estudo foi desenvolvido junto ao pessoal de enfermagem e limpeza atuantes nos centros obstétricos de três hospitais gerais localizados em área periférica da cidade de São Paulo. Estes atendiam à população de seis bairros da Zona Leste do Município e pertenciam à mesma região delimitada pelo SUDS (Sistema Unificado e Descentralizado de Saúde).

A região em estudo apresentou 59 casos de AIDS confirmados no período de julho de 1982 a janeiro de 1988 (SECRETARIA DE ESTADO DA SAÚDE, 1988).

Dos hospitais pesquisados, um era de caráter filantrópico e atendia à média mensal de 400 partos; dois eram públicos e atendiam 200 e 250 partos mensais respectivamente. Os serviços de obstetrícia dos hospitais pesquisados já haviam atendido a dois, um e nenhum caso confirmado de AIDS, respectivamente, até o momento da pesquisa.

A amostra constituiu-se de oito atendentes de enfermagem, uma auxiliar de enfermagem, quatro enfermeiras, uma obstetriz e três serviçais de limpeza escaladas no centro obstétrico dos hospitais em estudo. Para fazerem parte da amostra, as entrevistadas deveriam estar atuando no setor por período não inferior a trinta dias e estar de plantão na data em que foi efetuada a visita da entrevistadora ao local.

Para o levantamento de dados foram utilizados formulários específicos para atendentes e auxiliar de enfermagem, para enfermeiras e obstetriz e para serviçais da limpeza. Os mesmos foram aplicados pela autora em local privativo.

\section{RESULTADOS}

A tabulação dos dados coletados nos revelou que nas instituições pesquisadas não estavam sendo utilizado a solução recomendada pelo MINISTÉRIO DA SAÚDE (1987 e 1986b) e Secretaria de Higiene e Saúde do Município de São Paulo ${ }^{14}$ (glutaraldeído a $2 \%$, por 30 minutos) para a desinfecção do instrumental cirúrgico. O mesmo ocorria em relação à imersão de luvas, uma vez que é recomendado o emprego de hipoclorito de sódio a $1 \%$, por 30 minutos (MINISTÉRIO DA SAÚDE, 1986-b; SECRETARIA DE HIGIENE E SAÚDE, 1988). As soluções citadas pelas entrevistadas para imersão de luvas usadas foram as mesmas referidas para a imersão do instrumental (quaternários de amônio, iodo e formol).

O tempo de imersão do instrumental em solução para desinfecção fica na dependência da demanda do setor e não do período de atividade da solução utilizada; o mesmo ocorrendo com as luvas e amniótomos usados.

Não houve uniformidade entre as informações de tempo de imersão e solução empregadas entre os representantes das várias categorias de enfermagem de um mesmo serviço e sua chefia imediata; o mesmo foi verificado quanto a procedimentos pertinentes à desinfecção de comadres, acondicionamento de roupa suja de sangue, de placenta e do lixo das salas de parto, bem como quanto à solução empregada para a lavagem das mãos.

As enfermeiras obstétricas dos hospitais pesquisados demonstratam preocupação pela sua proteção quanto ao risco de contaminação pelo HIV, no entan. to, não foi verificada sua preocupação em avaliar e diminuir a ansiedade de seu pessoal sobre a AIDS.

Do pessoal de enfermagem pesquisado, $100 \% \mathrm{fa}-$ zia uso de luvas para limpeza de material e instrumental utilizados no centro obstétrico, bem como para a reanimação do recém-nascido em sala de parto. Para a limpeza de sala de parto, o manuseio de roupas sujas de sangue e a punção venosa, o uso de luvas ficava a critério de cada indivíduo.

As soluções citadas como de uso para lavagem das mãos, não atendem às recomendações dos órgãos of iciais para a proteção contra o HIV.

O emprego de óculos de proteção durante o procedimento do parto foi citado por $80 \%$ das enfermeiras pesquisadas e os mesmos não são fornecidos pelas instituições.

Verificou-se ainda que as placentas eram embaladas em saco plástico único e encaminhadas para a coleta de lixo hospitalar. Não havia identificação como material potencialmente infectado. $\mathrm{O}$ mesmo ocorria com o lixo do centro obstétrico.

Foi citado por $100 \%$ do pessoal da limpeza pesquisado, a utilização de luvas de borracha durante seu trabalho diário no centro obstétrico; enquanto que $33 \%$ citaram o uso de botas de borracha e 33\%, o avental de tecido sendo utilizado como proteção. Não foi citado o uso de avental de plástico.

As soluções empregadas para limpeza de pisos 
e superfícies sujas de sangue do centro obstétrico e citadas pelas serviçais da limpeza eram o quaternário de amônio com água e o sabão com "cândida". Na única instituição que empregava a "cândida" para a limpeza, a funcionária referiu que dilui ainda mais a solução que recebe por considerá-la forte.

Os serviços de educação, continuada dos hospitais pesquisados não promoviam orientações sistematizadas sobre AIDS aos funcionários do centro obstétrico.

$O$ elemento mais atuante na orientação do funcionário quanto à AIDS foi citado com sendo o médico da Comissão de Controle de Infecção Hospitalar.

Não foi observada preocupação para adaptação das fichas obstétricas, a fím de identificação de parturientes pertencentes aos grupos de risco, dificultando o reconhecimento das mulheres $\mathrm{HIV}$ positivas e, por tanto, amp iando o risco de contaminação da equipe.

$O$ pessoal de enfermagem demonstrou utilizar os recursos of erecidos pelas instituições para prevenção de contaminação, no entanto, estes não cobrem os riscos de infecção pelo HIV.

Os enfermeiros entrevistados não freqüentaram cursos de atualização para obterem maiores embasamentos sobre a doença e sua transmissão.

As instituições de caráter público of erecem maiores recursos a seus funcionários, no sentido de prevenção de contaminação pelo HIV em comparação com o hospital filantrópico pesquisado. No entanto, nenhum deles possui rotinas sistematizadas específicas para AIDS no centro Obstétrico.

\section{COMENTÁRIOS}

Pelos resultados otidos, verifica-se que nos centros obstétricos pesquisados, não havia emprego correto de associação entre soluções para a desinfecção de material e instrumental que levasse à prevenção do risco ocupacional de contaminação pelo HIV. Igualmente, verifica-se que não havia uniformidade de procedimentos preventivos entre os elementos de enfermagem de um mesmo serviço.

As discordâncias das respostas entre as entrevistadas de mesmo nível hierárquico entre si e com a chefia imediata demonstraram o não estabelecimento de rotinas de serviço e a não preocupação da enfer. meira do setor em supervisionar o trabalho de seu pessoal.

As soluções utilizadas para a limpeza de pisos e superfícies sujas de sangue nos centros obstétricos dos três hospitais pesquisados não atendiam às especificações do ministério da Saúde para a inativação do HIV; portanto, percebe-se que não havia proteção contra o vírus da AIDS nos pisos das unidades estudadas, ha vendo a necessidade de orientação do pessoal de limpeza destes serviços.

Os resultados mostraram também que o enfermeiro do centro obstétrico não foi representado conıo orientador de seu pessoal a respeito do tema AIDS. Observou-se ainda que os conhecimentos sobre a doença dependem de cada indivíduo que deve procurar fora do ambiente de trabalho as informações de seu interesse.

Como conseqüência da busca individual, pode haver defasagem no conhecimento do pessoal quanto à doença e o conseqüente aumento de sua preocupação com a mesma.

A utilização de barreiras de proteção contra o HIV durante determinados procedimentos de enfermagem ficava a critério de cada funcionário do centro obstétrico e o enfermeiro da unidade demonstrou não interferir em tal ação.

\section{CONCLUSÃO}

Embora o risco de transmissão ocupacional do HIV seja baixo, vem aumentando o número de mulheres infectadas assistidas pelos serviços obstétricos e a negligência quanto a aspectos preventivos pode contribuir para a maior disseminação da AIDS.

Ao analisar o papel da enfermeira obstétrica como líder do pessoal de enf ermagem do centro obstétrico e sua função de administradora, prestadora de assistência e educadora para a saúde; verifica-se que nos centros obstétricos pesquisados sua liderança não se faz sentir de maneira a contribuir para a diminuição da ansiedade da equipe quanto à contaminação pelo HIV, quer orientando-a quanto a aspectos preventivos, quer supervisionando-a, quer formulando rotinas para o atendimento da clientela visando uniformizar condutas de enfermagem frente ao risco da doença.

Os dados obtidos com este estudo permitem sugerir às enf ermeiras obstétricas que:

- participem de cursos de atualização sobre AIDS, a fim de terem embasamento suficiente e assim orientarem adequadamente seu pessoal;

- elaborem manuais de procedimentos e rotinas específicos para atuação frente à AIDS (declarada ou não) no centro obstétrico;

- exijam que o pessoal de enfermagem e de limpeza atuantes no centro obstétrico utilizem barreiras protetoras contra o HIV;

- exi jam da administração da instituição de trabalho o fornecimento de soluções adequadas à inativação do HIV;

- elaborem e participem de programas sistematizados de orientação sobre AIDS aos funcionários do centro obstétrico;

- promovam alterações na ficha obstétrica para possibilitar identificação de mulheres do grupo de risco para AIDS;

- promovam ambiente livre de estresse para parturientes através de orientação de seu pessoal sobre as vias de transmissão do HIV e sua prevenção;

- conheçam as recomendaões para proteção contra a contaminação pelo HIV elaboradas pelos órgãos oficiais de saúde, adotando-as;

- participem de programas de educação continuada sobre AIDS para equipes de outros serviços da unidade hospitalar;

- assistam às parturientes e aos recém-nascidos como indivíduos potencialmente infectados pelo HIV; 
- colaborem em programas de educação para a saúde desenvolvidos junto à gestante e/ou puérperas, cujo tema seja AIDS;

- supervisionem o pessoal do centro obstétrico durante seu trabalho;

- mantenham-se atualizadas e a sua equipe, em assuntos pertinentes à AIDS e à transmissibilidade do HIV.

Acreditamos que a enfermeira obstétrica deve se envolver efetivamente em programas de saúde que visem diminuir a disseminação da AIDS perinatal e do risco ocupacional.

\section{REFERÊNCIAS BIBLIOGRÁFICAS}

1 FRIEDLAN, G. H. \& KLEIN, R. S. Transmission of the human imnunodeficiency virus. The England Journal of Medicine. 317(18): 1125-35, Oct. 1987.

2 FUCHS, D. et alii. HIV seroconversion in health care workers (letter). Journal of the American Medical Association. 258(18): 2525-26, Nov 1987.

3 GRIMES, D. A. The CDC and abortion in HIV-positive women (letter). Journal of the American Medical Association. 258(9): 1176, Sept. 1987.

4 LEADS from the MMWR. Prospective evaluation of health-care workers exposed via parenteral or mucous membrane routes to blood and body fluids of patients with AIDS. Journal of the American Medical Association. 251(16): 2071-5, April, 1984.

5 LIMA, M. B. C. AIDS - a doença do medo. Rio de Janeiro, MEDSI, 1986. 77p.

6 LISKIN, L. \& BLACKBUR, R. AIDS - uma crise de saúde pública. Population Reports, Maryland, 1(6), Abr. 1987. 42p.
7 MINISTÉRIO DA SAÚDE. Secretaria Nacional de Programas Especiais de Saúde. Centro Nacional de Referência para AIDS. Divisão de Dermatologia Sanitária. AIDS/SIDA: recomendações para hospitais, ambulatórios médicos, odontológicos e laboratórios. São Paulo, 1986a, (mimeogr.)

8 . Secretaria Nacional de Ações Básicas de Saúde. Programa Nacional de Controle de Doenças Sexualmente Transmissíveis e AIDS. Centro de Documentação. Recomendações para prevenção e controle da infecção pelo vírus HIV (SIDA/AIDS). Brasília, 1987a. $27 p$.

9 . Secretaria Nacional de Programas Especiais de Saúde. Divisão Nacional de Dermatologia Sanitária. Centro Nacional de Referência para AIDS. Recomendações para hospitais, ambulatórios médicos, odontológicos e laboratórios: normas e manuais técnicos. Brasília, 1986b. 17p.

10 . Boletim Epidemiológico. Recomendaçōes para o controle da infecção do HIV na gestação. Ano 1, no 2. Brasília, 1987b.

11 . Boletim Epidemiológico. AIDS. Recomendações para o controle de infecção do HIV na gestação. Ano 1, no 6. Brasília, 1987c.

12 PYUN, K. H. et alii. Perinatal infection with human imnunodeficiency virus: specific antibody responses by the neonate. New England Journal of Medicine. 317(10): 611-14, Sept. 1987.

13 SECRETARIA DE ESTADO DA SAÚDE. Sistema Unificado e Descentralizado de Saúde. São Paulo, 1988. Mimeogr.

14 SECRETARIA DE HIGIENE E SAÚDE. Manual de Normas de Controle de AIDS. São Paulo, 1988. Mimeogr.

15 STONE, Y. \& COWAN, L. To screen ... or not to screen? Nursing Times. 83(28): 66-67, July 1987. 